\title{
MITOS CONSTRUÍDOS CULTURALMENTE E IDEALIZAÇÃO DO BOM ALUNO E DO MAU ALUNO: UMA PERSPECTIVA NEUROPSICOLÓGICA
}

\author{
CULTURALLY BUILD MYTHS AND IDEALIZATION OF GOOD STUDENT AND \\ DOMAED STUDENT: A NEUROPSYCHOLOGICAL PERSPECTIVE
}

\author{
Enerlaine Nogueira - UCAM/Brasil
}

\begin{abstract}
RESUMO: $\mathrm{O}$ artigo tem o objetivo de discutir sobre mitos construídos culturalmente e a idealização do bom aluno e do mau aluno numa perspectiva neuropsicológica, considerando o construto inteligência e as relações que se estabelecem em sala de aula. Neste sentido, optou-se por uma pesquisa bibliográfica e, diante dos estudos realizados, percebeu-se que se torna relevante desmistificar as concepções construídas socialmente que vinculam automaticamente o comportamento do aluno à inteligência. Ainda há muito que se questionar e discutir, no intuito de apontarmos outros fundamentos que direcionem as pesquisas que envolvam a inteligência na sala de aula, principalmente no que se refere à sua relação com o comportamento, para que possamos contribuir com a prática educacional dos professores. Nesta perspectiva, a escola se vê diante de um desafio que é agregar sua prática teórico pedagógica às contribuições da neuropsicologia, visando a compreensão e melhor direcionamento do potencial de seus alunos. Os professores são, consequentemente, os principais intermediários, recorrendo às estratégias de estudos e de projetos que sinalizem a promoção de um ensino compromissado com as reais necessidades dos alunos, por isso ao compreendemos o processo de aprender, considerando os múltiplos aspectos que o constitui, é possível adotar uma ação pedagógica que considere os diferentes elementos que influenciam a aprendizagem e desenvolvimento do aluno.
\end{abstract}

Palavras-chave: Aluno. Inteligência. Neuropsicologia. Professor.

ABSTRACT: The purpose of this article was to study neuropsychology studies about the behavioral trends that determine the student / teacher relationship; to understand how the process of idealization of the good student and the bad student occurs, to identify the contributions of existing knowledge about the neuropsychological foundations of intelligence involved, both in the teaching / learning process and in the relationships established in the classroom. In this sense, we opted for a bibliographical research and, in view of the studies carried out, it was realized that it becomes relevant to demystify the socially constructed conceptions that automatically link the behavioral aspect of the student to intelligence. However, there is still much to be questioned and discussed, in order to point out other fundamentals that guide the research involving intelligence in the classroom, especially as it relates to the behavioral aspect, so that we can contribute to the practice of teachers. In this perspective, the school faces a challenge that is to add its theoretical pedagogical practice to the contributions of neuropsychology, in order to understand and better target the potential of its students. Teachers are therefore the main intermediaries, using study and project strategies that signal the promotion of a commitment to the real needs of the students, knowing that when we understand the process of learning, considering the multiple aspects that constitute it, we adopt a more competent action taking into account the influence of the student as a whole in the construction of the future.

Educação, Psicologia e Interfaces, Volume 3, Número 1, p. 95-103, Janeiro/Abril, 2019. 
Keywords: Intelligence. Neuropsychology. Student. Teacher.

\section{INTRODUÇÃO}

Desde tempos remotos até início do século $\mathrm{XX}$, a relação professor-aluno é permeada pela supremacia da autoridade do professor diante de uma postura receptiva do aluno, que não promove diálogo entre ambos no transcorrer da aula. O professor é detentor do saber e transmite o conteúdo a ser absorvido, perpetuando o processo de aprendizagem de forma receptiva e mecânica. O conhecimento é verificado através de avaliações e recompensado positivamente com notas altas ou negativamente com notas baixas. Após esse período se observa uma expressiva mudança de paradigmas. Desde o final do século XX, essas mudanças vêm propondo à educação se inserir no campo da didática e de um ensino que apresente formas mais compatíveis com a complexidade, as variações, a velocidade, o dinamismo e pluralismo que se verifica na contemporaneidade. (LIBÂNEO, 1986, p. 24).

O pressuposto para dar início à esta análise é o entendimento de Vygotsky (1993) de que a aprendizagem é determinada por um processo histórico-cultural e devemos considerar que, estando o indivíduo sujeito às mediações históricas, entende-se que a demanda de ensino e consequente aprendizagem é resultante, não apenas dos recursos pedagógicos, mas também das relações subjacentes à estas. Sendo assim, é importante olhar para o aluno como parte constituinte na relação com o outro dentro do contexto educacional, onde a atuação do professor é fundamental, pois este exerce a função de mediador/facilitador da aprendizagem do aluno.

Portanto, a sala de aula se apresenta como um dos espaços mais oportunos para a construção de práticas que se realizam numa interação constante desse processo. Partindo desse entendimento destaca-se aqui o papel de cada aluno, este agora visto como indivíduo, antes compreendido como ser passivo e, atualmente, em pleno desenvolvimento de seu protagonismo no processo educativo tornando necessária uma compreensão por parte da escola.

Apesar de ser possível quantificar os múltiplos fatores envolvidos nas funções que caracterizam a capacidade intelectual, para os estudiosos da neuropsicologia como

Educação, Psicologia e Interfaces, Volume 3, Número 1, p. 95-103, Janeiro/Abril, 2019. 
Mitos construídos culturalmente e idealização do bom aluno e do mau aluno: uma perspectiva neuropsicológica

Mäder, Thais e Ferreira (2004), uma pessoa considerada inteligente é aquela que raciocina, se adapta mais facilmente ao meio, resolve problemas e é criativa. Diante do exposto é justificável que os neuropsicólogos e os profissionais da educação busquem um diálogo que contribua para o aperfeiçoamento de metodologias que sejam adequadas para facilitar, da melhor maneira, o desenvolvimento potencial de seus alunos e neutralizar os rótulos constituídos socialmente. Neste sentido, o artigo tem o objetivo de discutir sobre mitos construídos culturalmente e a idealização do bom aluno e do mau aluno numa perspectiva neuropsicológica, considerando o construto inteligência e as relações que se estabelecem em sala de aula.

\section{METODOLOGIA}

O caminho percorrido neste trabalho teve como norteadores a busca da compreensão acerca do processo de construção da concepção de aluno bom e aluno mau e sua relação com a inteligência. E também a investigação sobre a contradição existente entre o aluno ideal e o aluno real e suas determinações na prática docente e as contribuições da neuropsicologia e sua tarefa desmistificadora quanto ao que é concebido como bom e mau.

Para melhor entendimento do tema, optou-se pela revisão teórica, desta forma, o modelo de análise aqui apresentada tem como método a pesquisa qualitativa, por se tratar de questões subjetivas, ou seja, esta tem como objetivo primordial investigar os aspectos que envolvem os significados, as crenças, os valores e as atitudes. Para a elaboração deste estudo utilizou-se a pesquisa bibliográfica consultando alguns autores, dentre eles: Casares; Caballo e Marinho (2002), Libâneo (1986), Mäder, Thais e Ferreira, (2004), Oliveira (2005), Vygotsky (1993), dentre outros que trouxeram grandes contribuições para a apreensão do tema.

\section{MITOS CONSTRUÍDOS E IDEALIZAÇÃO DO BOM E MAU ALUNO}

Segundo Cordeiro, Donaduzzi e Schlindwein (2008) o ambiente educacional é constituído a partir de um recorte de realidade social, onde emerge a relação professor/aluno e os fenômenos educacionais que não são exclusivos da sala de aula, mas são produtos de representações sociais, determinantes históricos, educacionais e socioculturais que direcionam a ação pedagógica do professor. Assim, de maneira genérica, as representações do professor a respeito de seus alunos são construções 
simbólicas em que o aluno disciplinado, participativo, estudioso, que conquista boas notas é considerado o bom aluno, pois gera o comportamento que dele se espera. Em contrapartida, o considerado mau aluno, representa a parcela dos que não gostam de estudar, têm notas ruins, não participam das aulas, não apreciam atividades escolares, não se interessam pelas aulas, não demonstram motivação para aprender. Desses, a maioria vai à escola porque é obrigada e são vistos como geradores de um comportamento indesejável que deve ser corrigido.

Inadvertidamente essa concepção de aluno bom e aluno mau está intimamente ligada a ideia de inteligência. A Inteligência se constitui em um sistema cognitivo superior muito complexo que implica inúmeros outros processos, como: memória, atenção, motivação, raciocínio, esquemas de aprendizagem, resolução de problemas, etc. De acordo com Mäder, Thais, Ferreira, (2004, p. 63):

[...] a inteligência reflete a soma das experiências aprendidas pelo indivíduo. As definições enfatizam a habilidade de se adaptar ao meio; de aprender; de pensar de modo abstrato (usando símbolos e conceitos). Embora seja possível mensurar vários aspectos da habilidade intelectual, uma pessoa inteligente é aquela que raciocina, se adapta ao meio, aprende, resolve problemas e também é criativa.

Segundo as supracitadas autoras, o desenvolvimento neuropsicológico acontece através de uma relação dinâmica e constante das experiências adquiridas a partir da socialização e do contexto ambiental, e, faz-se necessário considerar os múltiplos fatores que interferem nesse processo, assim como a influência dos mesmos no desenvolvimento individual.

Não se pretende nessa pesquisa entrar nos méritos das disfunções fisiológicas ou dos transtornos cognitivos, pois queremos aqui chamar atenção para os mitos construídos culturalmente no contexto educacional e, a partir de uma "inquietação", nos deparamos com a questão: Por que alunos "bons" são comportados, conquistam boas notas e são queridos dos professores e, alunos "maus" são indisciplinados e tidos como problemáticos?

O contexto escolar na maioria das vezes tende a considerar todos os alunos sob uma visão homogênea, não dispensando a devida importância às suas histórias de vida e suas reais necessidades. Segundo Oliveira (2005, p. 38) "Toda indisciplina tem uma causa e que a mesma não é simplesmente uma ação, mas uma reação, e que existem vários 
Mitos construídos culturalmente e idealização do bom aluno e do mau aluno: uma perspectiva neuropsicológica

fatores determinantes da indisciplina, e um deles é a família”. Então, depreende-se que os indivíduos ao iniciarem a vida escolar, carregam consigo os valores, hábitos, frustrações, agressividade, revoltas, etc., que refletem a (mal) educação que recebeu noutros contextos, e que colabora para seu comportamento impróprio na sala de aula.

No entanto, esse aluno acaba por chamar a atenção dos professores e da família e, se for assistido de maneira satisfatória do ponto de vista cognitivo/afetivo/emocional, levando-se em consideração sua etapa do desenvolvimento maturacional, receberá a atenção necessária para aprender a lidar consigo e com os outros de modo a desenvolver suas potencialidades de maneira saudável. Por outro lado, por vezes, alunos quietinhos, obedientes e exemplares, que têm sobre si alta expectativa por parte de familiares e professores, na verdade podem apresentar certo grau de timidez, baixa autoestima e ansiedade diante das relações de autoridade e ainda pode haver uma agressividade velada e sinalizadora de dificuldades futuras. Nem sempre a introspecção significa conformidade social. Às vezes é o inverso, a docilidade e a introspecção podem estar escondendo a inquietude e isolamento de um indivíduo que não sabe como se manifestar, tem dificuldade em tentar mudar o que o constrange ou expressar algum sofrimento ou frustração que vai minando aos poucos sua criatividade, por medo do fracasso ou medo de desapontar aqueles que lançam sobre ele suas expectativas (CASARES, CABALLO; MARINHO, 2002, p. 196-201).

Em contrapartida, aqueles que já receberam o estigma de "maus alunos" podem ter características importantes para um bom desenvolvimento cognitivo: são corajosos para expressarem o que pensam e como se sentem, são criativos e possuem traços de liderança perante a turma, porém, na maioria das vezes, os comportamentos que não se ajustam à "normalidade" acabam por ofuscar esses talentos e, por conta disso, essas características geralmente não são exploradas pelos professores. Esse ofuscamento tornase gerador e mantenedor de uma contradição existente entre aluno ideal e aluno real, o que por sua vez, determina a prática pedagógica e a coloca diante de dificuldades em construir um espaço educativo.

Para Magalhães (1992, p. 45 apud RENCA, 2008) "a proximidade do aluno relativamente ao professor influencia quer o processo de aprendizagem, quer o comportamento do aluno [...]". O tipo de comunicação que se estabelece entre os alunos e o professor pode produzir uma aproximação ou distanciamento entre eles, desta forma, os que não estão ligados a essa comunicação de maneira satisfatória têm dificuldade para 
concentrar-se e tendem a distrair-se das suas atividades. O papel do educador na construção dessa comunicação é de possuir conhecimento, adequar a metodologia diversificando-a e utilizá-la para alcançar êxito na aprendizagem do aluno (MAGALHÃES, 1992).

[...] o comportamento indisciplinado resultará do nível de desenvolvimento cognitivo e moral do indivíduo, bem como da interpretação que este faz das situações, a qual é influenciada por outros processos cognitivos. São exemplo desses processos as representações, as expectativas, o autoconceito. A modificação comportamental poderá conseguir-se utilizando estratégias de ação preferencialmente cognitivas, como o desenvolvimento da autoinstrução e da autoobservação que permitam o desenvolvimento do autoconceito e da autoestima (MAGALHÃES, 1992, p. 25).

Para Freitas e Cardoso (2015) o desenvolvimento cognitivo estabelece relação de troca entre aprendizagem e comunicação com o meio onde vive e para o qual se direciona. Há aspectos biopsicossociais da aprendizagem que dependem de fatores como a captação da informação e o armazenamento do conhecimento, por isso, identificar como o indivíduo aprende ajuda os professores no processo de ensino.

Ainda conforme esses autores a neuropsicologia é uma forte aliada no sentido de desmistificar a complexidade que existe na educação/aprendizagem, visto que contribui para ampliar os olhares dos profissionais e da família sobre como o processo de aquisição da aprendizagem se desenvolve, assim como diversificar e aperfeiçoar a forma como ensinar. Ajudando, assim o professor e o aluno a se aproximarem do conhecimento.

Através de avaliações que forneçam informações mais precisas sobre o perfil cognitivo, tais como níveis de atenção, memória, velocidade de processamento, dentre outras, será possível a elaboração de programas de educação cognitiva, assim como orientações específicas para o contexto escolar (FREITAS; CARDOSO, 2015 p. 170).

Assim, além de caracterizar o funcionamento cognitivo enfatizando as potencialidades, a Neuropsicologia pode contribuir para desenvolver uma adaptação necessária no processo de ensino/aprendizagem. As grandes dificuldades tanto de comportamento quanto de aprendizagem, podem desta forma ser reconhecidas, proporcionando as metodologias educacionais adequadas na direção de diminuir e até mesmo neutralizar os déficits educacionais, contribuindo com os pais, com os professores 
Mitos construídos culturalmente e idealização do bom aluno e do mau aluno: uma perspectiva neuropsicológica

e principalmente desconstruindo os mitos que desqualificam e rotulam os alunos e consequentemente os futuros adultos.

\section{CONSIDERAÇÕES FINAIS}

Num consenso geral é esperado que os que são bons alunos se tornem futuros adultos competentes, que conquistem o sucesso em suas carreiras profissionais, que sua inteligência lhe abra caminhos para uma vida bem-sucedida e próspera. Da mesma forma é esperado que os maus alunos se tornem perdedores, que tenham subempregos, baixos salários, poucas oportunidades de sucesso devido à sua "pouca inteligência". Mas isso pode ser uma generalização histórica/cultural, pois se buscarmos na própria história da humanidade, há os que foram bons alunos de inteligência mediana, assim como há os que foram maus alunos de um intelecto invejável.

Assim, a sociedade, os docentes e a família das crianças, adolescentes e jovens em etapa escolar, devem ter consciência de que as concepções que sustentam o mito do bom e do mau aluno precisam ser desconstruídas, em favor do discernimento de que o desejo por ser aceito, as frustrações muitas vezes trazidas de outros contextos, inclusive familiar, a insegurança e o medo que causam ansiedade, podem estar camuflados por um comportamento passivo e aceitável.

A escola, primordialmente, pela influência que exerce na formação de identidade de seus alunos, deve ter em seu quadro profissional, educadores que valorizem o entendimento dos aspectos subjetivos do campo afetivo, emocional, intelectual, cultural, etc., buscando sempre ter um olhar mais abrangente e despido de rótulos. Neste sentido, a neuropsicologia tem muito a oferecer, pois se trata de uma ciência que tem como propósito elementar investigar as relações entre cérebro e comportamento, em que a maioria dos profissionais dessa área direcionam seus estudos para o campo das funções mentais superiores.

As funções cognitivas como: atenção, memória, linguagem, funções executivas, etc., têm relação íntima com o desenvolvimento da aprendizagem, que reverberam na maneira como desempenhamos as atividades, desde as mais simples até as mais complexas. Os conhecimentos do neuropsicólogo poderão auxiliar os educadores e outros profissionais em sua atuação. Ele poderá atuar em instituições de ensino, realizando pesquisas que promovam a integração dos saberes e principalmente desmitifiquem a concepção de que certos alunos não conseguem adquirir a aprendizagem

Educação, Psicologia e Interfaces, Volume 3, Número 1, p. 95-103, Janeiro/Abril, 2019.

ISSN: 2594-5343. DOI: https://doi.org/10.37444/issn-2594-5343.v3i1.151 
por "preguiça ou por burrice" taxando-os de maus alunos. Além disso, são vários os transtornos e dificuldades da aprendizagem que ocorrem pelo mal funcionamento das funções cognitivas. Alguns déficits e comportamentos tidos como anormais podem ser compreendidos após uma avaliação neuropsicológica.

\section{REFERÊNCIAS BIBLIOGRÁFICAS}

CASARES, M.I.M; CABALLO, V.E; MARINHO, M.L. A criança tímida e retraída. Pediatria, Moderna, 38(5): 196-201, maio 2002. Disponível em:

http://www.moreirajr.com.br/revistas.asp?fase $=$ r003\&id_materia=1920. Acesso em: 14/jul./2018.

CORDEIRO, MH; DONADUZZI, A.; SCHLINDWEIN, SM. Psicologia e educação:

Representação social do bom aluno: implicações éticas na educação. In: PLONER, KS., et al., (Org). Ética e paradigmas na psicologia social [online]. Rio de Janeiro: Centro Edelstein de Pesquisas Sociais, 2008. p. 152-162. Disponível em:

http://books.scielo.org/id/qfx4x/pdf/ploner-9788599662854-13.pdf. Acesso em: 10/jul./2018.

FREITAS, Patrícia M; CARDOSO, Thiago G. S. Contribuições da Neuropsicologia para a inclusão educacional: como enfatizar as potencialidades diante das deficiências? APRENDER - Cad. de Filosofia e Psic. da Educação, Vitória da Conquista, Ano IX n. 14 p. 153-173, 2015. Disponível em:

http://periodicos.uesb.br/index.php/aprender/article/viewFile/5305/5088. Acesso em: 14/ago./2018.

LIBÂNEO, José Carlos. Democratização da escola pública. A pedagogia HistóricoCrítico social dos Conteúdos. São Paulo: Loiola, 1986.

MÄDER, M. I; THAIS, M. E. R. DE O.; FERREIRA, M. G. R. Inteligência: um conceito amplo, 2004. In: ANDRADE, V. M.; SANTOS, F. H.; BUENO, O. F. (Orgs.) Neuropsicologia hoje. São Paulo: Artes Médicas, 2015.

OLIVEIRA, Maria Izete. A indisciplina escolar: determinações, consequências e ações. Brasília: Líber Livro, 2005.

MAGALHÃES, O. Verso e Reverso: Os alunos, os professores e a indisciplina, 1992. In: RENCA António A. A Indisciplina na Sala de Aula: Percepções de Alunos e Professores. Universidade de Aveiro - Departamento de Ciências da Educação, 2008. Disponível em: https://ria.ua.pt/bitstream/10773/1045/1/2009001357.pdf. Acesso em: 14/ago./2018.

VYGOTSKY, L. S. Pensamento e Linguagem. São Paulo: Martins Fontes, 1993.

Educação, Psicologia e Interfaces, Volume 3, Número 1, p. 95-103, Janeiro/Abril, 2019.

ISSN: 2594-5343. DOI: https://doi.org/10.37444/issn-2594-5343.v3i1.151 
Mitos construídos culturalmente e idealização do bom aluno e do mau aluno: uma perspectiva neuropsicológica

\section{Credenciais da/os autora/es}

NOGUEIRA, Enerlaine -Psicóloga graduada pela Universidade Paulista - UNIP de Araraquara. Pós-graduada Lato Senso - Docência do Ensino Superior e Neuropsicologia pela Universidade Cândido Mendes - UCAM - BRASIL. E-mail: laine.nogueira7@yahoo.com

Endereço para correspondência: Enerlaine Nogueira. Av. Abel Américo, n.503, Residencial Cambuy CEP 14805-410, Araraquara/SP. E-mail:

laine.nogueira7@yahoo.com

Como citar este artigo (Formato ABNT): NOGUEIRA, Enerlaine. Mitos construídos culturalmente e idealização do bom aluno e do mau aluno: uma perspectiva neuropsicológica. Educação, Psicologia e Interfaces, v. 3, n.1, p. 95-103, 2019. DOI: https://doi.org/10.37444/issn-2594-5343.v3i1.151

Recebido: 04/01/2019.

Aceito: 20/03/2019. 